\title{
Two Variable Method for Fault Analysis in Grid Tied Solar Photovoltaic System
}

\author{
Megha Khatri $^{\# 1}$, Atul Kumar ${ }^{\# 2}$ \\ ${ }^{\#}$ School of Engineering and Technology, Ansal University, Gurgaon, India. \\ ${ }^{1}$ meghakhatri@ansaluniversity.edu.in \\ 2atulkumar@ansaluniversity.edu.in
}

\begin{abstract}
To increase the efficiency and reliability of a grid tied solar PV plant, it is important to detect the possible abnormalities and their location in the system. Conventional power devices frequently fails to detect certain types of faults which occur due to inappropriate installation, varying plant conditions and environmental factors such as low irradiance, snow, clouds, bird dropping, dust accumulation. Therefore, it is necessary to identify a vital solution to deal with the internal and external faults of the system. The faults in photovoltaic modules, array strings and inverter sometimes leads to safety issues in the system. This paper proposes a simple two-variable method to detect faults under the abnormal operating conditions of grid tied solar photovoltaic system. Furthermore the internal and external faults are studied using an experimental setup and obtained results indicate the accurate analysis of the fault severity and the change in electrical parameters of the system can be observed and compared with the normal working condition of system.
\end{abstract}

Keyword- Grid-Tied PV system, Inverter fault, Array fault, Fault detection.

\section{INTRODUCTION}

Popularity of photovoltaic systems is increasing rapidly worldwide due to the simplicity of installation, no fuel cost, less maintenance and long life. The energy produced by the plants depends upon various factors such as performance characteristics of plant components, geometrical configuration, electrical and mechanical parameter and weather conditions of the site and availability of amount of solar irradiance. The power production capacity of the grid tied photovoltaic (PV) plants ranges from few kilowatts to several megawatts depending upon their usage for domestic to utility scale. The maximum power production of plant reduces in case of abnormality in the system. The conventional protection devices of PV plant consist of over current interrupters, protection relays, ground fault and arc-fault protection devices frequently fails to detect the faults under certain conditions[1]. The challenge is to protect the system from the abnormalities due to protection equipment failure, environmental conditions, maximum power point tracker, blocking diodes and PV module shading. The faults in the system can be detected by comparing the actual electrical parameters which depend upon the system configuration parameters and meteorological data of the plant site with the expected quantities of the system [2]. Thresholds are defined considering PV array parameters such as the amount of irradiance incident at the normal of flat plate collector surface, ambient temperature and electrical quantities of the system so as to detect the presence of abnormalities.

Currently, many researchers are working on identifying the techniques to detect the PV system faults in minimum possible time to eliminate them from the system. To locate disconnect in the PV module string the earth capacitance measurement method was developed in [3], another technique that can detect the change in transmission line impedance with string disconnect is known as time-domain reflectometry [4]. Some researchers used statistical methods such as analysis of variance test and nonparametric Kruskale-Wallis test explaining offline supervision and real- time monitoring of the system is accurate and can be used for remote monitoring of the plant is proposed [5]. Others used the climate data with the help of satellite for the remote monitoring and fault detection method of small grid connected systems is presented [6], while some used climate data measured by sensors installed on the plant. A decision tree algorithm for fault diagnose was used [7] and the experimental data required for this is electrical and mechanical specifications of PV array. It was tedious to include all type of faults and their circumstances of occurrence in the training data set of decision tree algorithm. An outlier fault detection method using 3-Sigma, Hamper identifier and Boxplot rule uses string currents as input to detect the abnormality in the system was tested for finding the PV array faults has been proposed [8]. Wavelet transform based algorithm for fault detection is presented [9], has high cost of implementation because of need in modification in inverter circuit. An automatic fault detection method proposed [10] is based on the fuzzy rule based system can identify almost all type of faults; however in some faulty conditions it gives false alarms. The artificial neural network based learning method is used to detect the faults in utility plants is presented [11] made the monitoring system simpler whereas having problems in training data hold circuits. An overview of various fault detection schemes and recommendations for improvement is given [12]. This paper proposes a two-variable method to detect the presence of faults in the grid tied PV system that can easily distinguish the nature of faulty i.e. permanent or temporary. The data set 
required to perform the experiment is easily available from the manufacturer and the thresholds are obtained by using basic mathematical formulas. The paper is divided into various sections explaining the types of faults, fault detection using simple calculations and experimental observation of the proposed method and conclusion is given in the last section.

\section{FAULTS IN PV SYSTEM}

Faults in the grid tied photovoltaic system are mainly categorized as internal and external faults as shown in figure 1. Internal faults are due to uncontrollable charging and discharging of battery unit, inappropriate operation of grid tied inverter unit and/or flaws in maximum power point tracking control, which effects the synchronization between grid and the plant. External faults in the system exist because of faulty cables and/or PV module/array. The external cable faults can be avoided by grounding the power equipments and system separately according to their power handling capacity. Even though the system is exposed to the faults such as line to ground, short circuit and open circuit faults occur due to the failure of earth fault detection devices. The mechanical damage to the cable such as insulation failure, potential difference in the connected modules and cable connectors leads to the bridging fault [13]. While the Arc- fault in the system takes place due to the reverse connections of modules, which results in large flow of current into the faulted string. Under this fault scenario, even the fuse does not work properly because of high voltage in the system during the fault, which may result in fire hazards. Due to these faults either current or voltage of the plant becomes uncontrollable, which may result in serious safety issues in the plant.

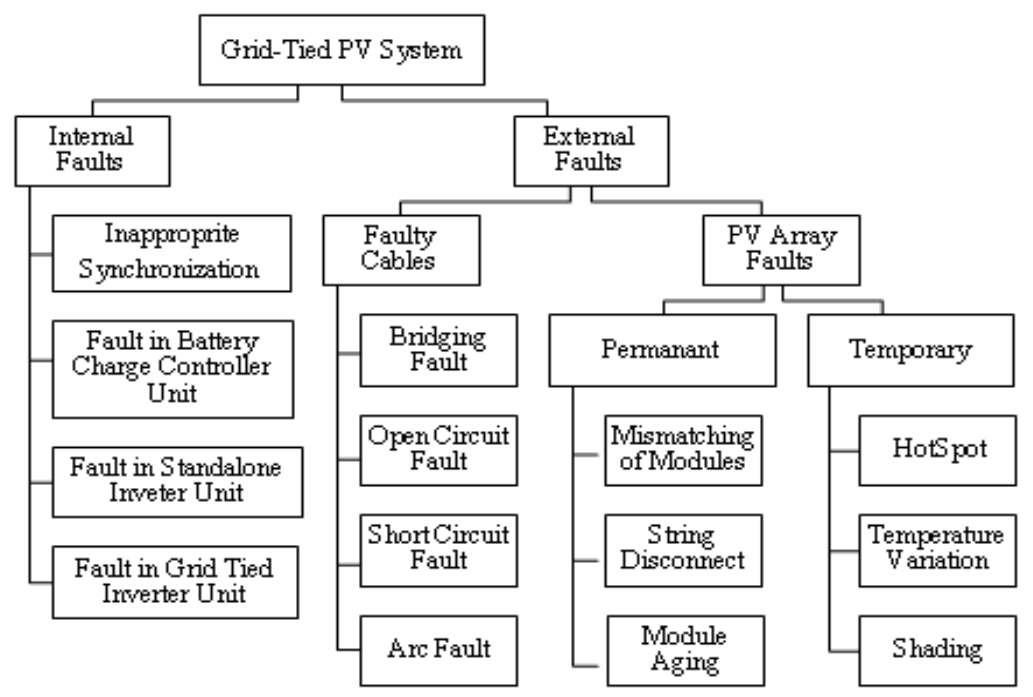

Fig.1. Classification of the faults in the photovoltaic system

Furthermore the PV array faults are classified as temporary and permanent faults in the system. To remove the permanent faults like mismatch in the electrical and mechanical parameters of modules connected in series and parallel, disconnect in the module string/failure of bypass/blocking diodes and cracks in the module layers (toughened glass or Ethyl Vinyl Acetate coating of the panel used to protect the cell), the PV modules needed to be either replaced with the new ones or disconnected from the system [14]. However, the temporary fault such as temperature variations because of change in time window of solar irradiance with respect to the change in season from summer to winter. A hotspot is also a temporary fault appears when a solar cell becomes reverse biased and dissipates power in the form of heat and total or partial shading of modules, reduces the instantaneous power output obtained from the plant. Hence any kind of abnormality impacts the efficiency, reliability and safety of a plant.

\section{A. Description of Grid Tied Photovoltaic System}

The PV array is connected to the virtual grid through short transmission line of inductance $3 \mathrm{mH}$ is shown in figure 2. The maximum power of $300 \mathrm{~W}$ peak can be injected to the virtual grid, while in case of fault occurrence, the power production capacity of a plant, the maximum power tracking ability reduces and affects the operating capability of the power converter as well. The bypass/ blocking diodes are connected with module allows the flow of current through the connected damaged module during the day time called bypass diode and the same diode blocks the reverse flow of current during night time is known as blocking diode employed in series and parallel so as to get the continuous output power from the array. 


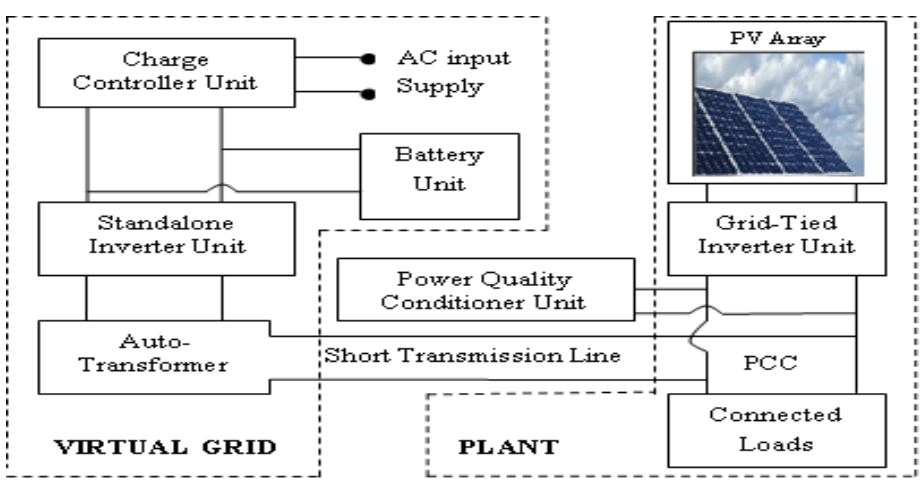

Fig.2. Block diagram representation of Grid-Tied photovoltaic system

The power quality conditioner unit is used to maintain the voltage, frequency and phase at the point of common coupling to synchronize the plant with grid. The specifications of grid tied photovoltaic system components are given in Table 1.

TABLE 1. Specifications of experimental system components

\begin{tabular}{|c|c|c|}
\hline Equipment & Type & Electrical Parameters \\
\hline \multicolumn{3}{|l|}{ Plant } \\
\hline PV-Module & Polycrystalline Silicon & $\begin{array}{l}\text { At STC: } P_{\max }=250 \mathrm{~W} \mathrm{~V} \mathrm{oc}_{\mathrm{oc}}=43.2 \mathrm{~V}, \mathrm{I}_{\mathrm{sc}}=7.5 \mathrm{~A}, \mathrm{I}_{\mathrm{mp}}=7.14 \mathrm{~A} \\
, \mathrm{~V}_{\mathrm{mp}}=35.0 \mathrm{~V}\end{array}$ \\
\hline PV-Array & $\begin{array}{l}\text { Connected two modules } \\
\text { in series }\end{array}$ & $\begin{array}{l}\text { At STC: } P_{\max , \text { array }}=500 \mathrm{~W} \quad V_{\mathrm{oc} \text {, array }}=86.4 \mathrm{~V}, \mathrm{I}_{\mathrm{sc} \text {, array }}=7.5 \mathrm{~A} \\
\mathrm{I}_{\mathrm{mp} \text {, array }}=7.14 \mathrm{~A}, \mathrm{~V}_{\mathrm{mp}, \text { array }}=70.0 \mathrm{~V}\end{array}$ \\
\hline Grid Tied Inverter & $\begin{array}{l}\text { Transformerless } \\
\text { configuration }\end{array}$ & $\begin{array}{l}\text { Maximum output power }=500 \mathrm{~W} \\
\text { Maximum efficiency feeding single phase }=94.8 \% \\
\text { Maximum power point voltage }=45-100 \mathrm{~V}\end{array}$ \\
\hline \multicolumn{3}{|l|}{ Grid } \\
\hline Standalone Inverter & Pure Sine wave & $\begin{array}{l}\text { Maximum peak output Power }=375 \mathrm{~W}_{\mathrm{p}} \\
\text { Night time power loss }=0.1 \mathrm{~W} \\
\text { Switch on power }=2 \mathrm{~W}\end{array}$ \\
\hline Auto-Transformer & & Voltage Range $=5-270 \mathrm{~V} \mathrm{AC}$, Current $=5-25 \mathrm{~A}$ \\
\hline $\begin{array}{l}\text { Charge Controller } \\
\text { Unit }\end{array}$ & $\begin{array}{l}\text { Mode of operation: } \\
\text { Automatic and Manual }\end{array}$ & $\begin{array}{l}\mathrm{V}_{\text {max,in }}=150 \mathrm{~V}, \mathrm{I}_{\text {max }, \text { out }}=10 \mathrm{~A} \mathrm{~V} \mathrm{~V}_{\text {out,automatic }}=78 \mathrm{~V}, \mathrm{~V}_{\text {gate,manual }} \\
=5 \mathrm{~V}_{\text {peak }}\end{array}$ \\
\hline
\end{tabular}

\section{B. Two Variable Method}

The proposed method uses readily available data i.e. instantaneous PV parameters such as maximum energy yield or output power from the plant, module insulation impedance, PV string current etcetera. This brings ease and flexibility in its implementation at large scale. It also focuses in reducing the efforts to find the line faults in individual PV module because it has been observed, sometimes it is difficult for the system over-current protection devices to detect the line faults in module than the array strings. So it is necessary to distinguish between the internal and external faults to act upon them accordingly to improve the reliability of the system. By analyzing the energy losses on the plant and grid side of the grid- tied PV system i.e. constant or variable energy losses the overall efficiency of the system can be realized [15]. The loss of energy in photovoltaic array can be obtained as

$$
\mathrm{L}_{\text {array }}=\left(\text { Expected } \mathrm{P}_{\text {max,array }}\right)-\left(\text { Instantaneous } \mathrm{P}_{\text {max,array }}\right)
$$

The instantaneous $\mathrm{P}_{\text {max,array }}=\mathrm{V}_{\mathrm{pv}}{ }^{*} \mathrm{I}_{\mathrm{pv}}$ in Watts depends upon the instantaneous plant voltage, current and other plant factors such as climatic conditions, module temperature, level of irradiance, PV shading, tilt angle of module, maximum power point tracking algorithm, mismatching, cable losses etcetera. Whereas the expected $\mathrm{P}_{\text {max,array }}=\mathrm{P}_{\mathrm{mp}}\left(\frac{\mathrm{G}}{\mathrm{G}_{\mathrm{r}}}\right)$, and $\mathrm{P}_{\mathrm{mp}}$ is the maximum power at standard test conditions. The plant side losses $\left(\mathrm{L}_{\text {plant }}\right)$ are also known as capture losses depends upon the above mentioned factors as well as the performance of other equipments used to connect the plant with load and grid. These losses can be calculated theoretically as

$$
\mathrm{L}_{\text {plant }}=\left(\frac{G_{\text {inst. }}\left(W h / m^{2}\right)}{G_{r}\left(1000 W / m^{2}\right)}\right)-\left(\frac{E_{\text {plant }}(W h)}{P_{r}(W)}\right)
$$


Where, $G_{\text {inst. }}$ is the total irradiance on the surface of solar flat plate collector and $G_{\mathrm{r}}$ represents the irradiance at standard test conditions(STC: irradiance $=1000 \mathrm{~W} / \mathrm{m}^{2}$, temperature $=25^{\circ} \mathrm{C}$, air mass. $=1.5$ ) and their ratio gives the reference energy yield by the plant in hour. The ratio of actual direct current energy produced in by plant $E_{\text {plant }}$ over the defined period of time (i.e. in a day, month or year) with the reference maximum power $P_{r}$ produced. The difference between these ratios gives plant side loss $\mathrm{L}_{\text {plant }}$. The losses occur in the grid side $\mathrm{L}_{\text {grid }}$ mainly depends upon the performance of inverter i.e. conversion efficiency from DC to AC power, auto transformer and the impedance of transmission line and can be mathematically calculated as

$$
\mathrm{L}_{\text {grid }}=\left(\frac{E_{\text {plant }}(W h)}{P_{r}(W)}\right)-\left(\frac{E_{\text {grid }}(W h)}{P_{r}(W)}\right)
$$

Where, the energy $\mathrm{E}_{\text {grid }}$ is the output $\mathrm{AC}$ energy transferred to the grid is produced by the plant after serving the load depends upon the inverter performance, where the grid tied inverter used in the experimental setup is giving overall efficiency $80-84 \%$. The performance ratio (PR) gives the idea about overall losses occur in the system over the time period i.e. a month or a year.

$$
\mathrm{PR}=\frac{E_{\text {system }}(W h)}{E_{\text {system, } \text { modelled }}(W h)}
$$

Where, $\mathrm{E}_{\mathrm{system} \text {,modelled }}=$ Irradiance $_{\text {measured on location }}\left(\frac{W h}{m^{2}}\right) *$ Active area of PV module $\left(\mathrm{m}^{2}\right) *$ module efficiency $(\eta)$. At the specified system parameters, the PR is $100 \%$ at the energy yield by the system $E_{\text {system. Typically achieved } P R}$ is $90 \%$ and above, while in case of abnormality in the system, it is found that the PR may vary from $45-65 \%$, which means the solar energy is not getting converted into useful electrical energy. The PR values influenced by solar irradiance, PV modules are shaded or dirty, recording period, all type of losses, efficiency of PV array and inverter and also on the size of plant, technology and site location [16].

It has been observed that theoretically the difference in calculated array losses $\mathrm{L}_{\text {array }}$ and the measured is zero when the system is working normally without any fault. However in practice, due to the uncontrollable losses in the system it should be compared with the preset threshold that is $2-7 \%$ as the expected error is less than the typically obtained error which is generally under $5 \%$. Hence the accuracy of both the calculated two variables in above equations (2) and (4) respectively depends upon the operational reliability of equipments as well. From the above simple calculations, the system condition can be found i.e. normal or faulty. Therefore with the help of digital power analyzers on the plant and grid side near point of common coupling of the experimental setup, the response of the system has been analysed under various conditions is discussed in the following section.

\section{Fault Analysis}

The analysis of voltage, current, array losses and performance ratio allows the identification of the type of fault. If the performance ratio is less then unity, it indicates the possibility of fault in grid tied inverter or in the cables connecting the grid to the plant because the output $\mathrm{E}_{\text {grid }}$ decreases and $\mathrm{L}_{\text {grid }}$ increases. While, if it is greater than unity, the energy produced by the plant $\mathrm{E}_{\text {plant }}$ decreases and $\mathrm{L}_{\text {plant }}$, which indicate the possibility of PV array fault. In this case the nature of fault can be identified based on their duration of occurrence and retention in the system.

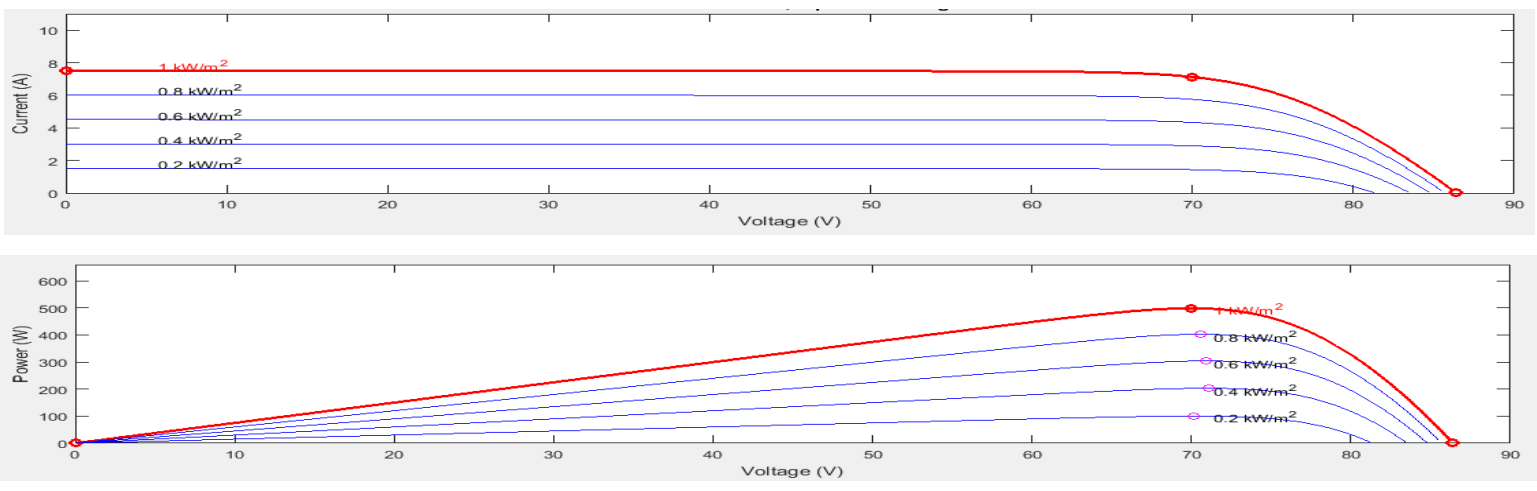

Fig.3. I-V and P-V curves at various irradiance levels

The error in maximum power point tracking, shading and disconnect in string of module can be analysed from the $\mathrm{i}-\mathrm{v}$ and $\mathrm{p}-\mathrm{v}$ curves of the plant. Shown figure 3 is representing the expected or ideal $\mathrm{i}-\mathrm{v}$ and $\mathrm{p}-\mathrm{v}$ curve of the plant at module temperature $25^{\circ} \mathrm{C}$ and showing the peak at various irradiance levels from $200 \mathrm{~W} / \mathrm{m}^{2}$ to $1000 \mathrm{~W} / \mathrm{m}^{2}$. The actual obtained $\mathrm{i}-\mathrm{v}$ and $\mathrm{p}-\mathrm{v}$ curve in case of different working condition is shown in figure 4.

The curves represent the actual power and current peaks, when the maximum power point tracker is working with more than $94 \%$ of efficiency. While it has also been observed that with the help of bypass diodes the power obtained at the output can be increased and the peak of $\mathrm{p}-\mathrm{v}$ curve can be improved as shown. 



Fig.4. I-V and P-V curves with different plant conditions

The total and partial shading of fixed PV modules can be either static or dynamic. The objects stick to the surface of the flat plate collector such as bird dropping, accumulation of dirt, water or leaves refers to the static shading of collector. However the dynamic shading on PV collector is caused by the trees, buildings and chimney varies with time. The power loss is higher in case of dynamic shading, which was artificially created by using the cardboard so as to cast a shadow on the PV module. The array losses $\left(\mathrm{L}_{\text {array }}\right)$ were recorded with the help of data logger and plotter unit. The graphs represented in figure 5 and 6 shows the change in level of irradiance at the latitude location of the plant during the solar window and the array losses during that interval in normal and faulty condition respectively. It has been observed that the total losses are lesser in case of normal working condition than the photovoltaic modules are shaded. figure 6 is showing that even in peak hours of solar window the losses are more than the normal working condition because of shading.

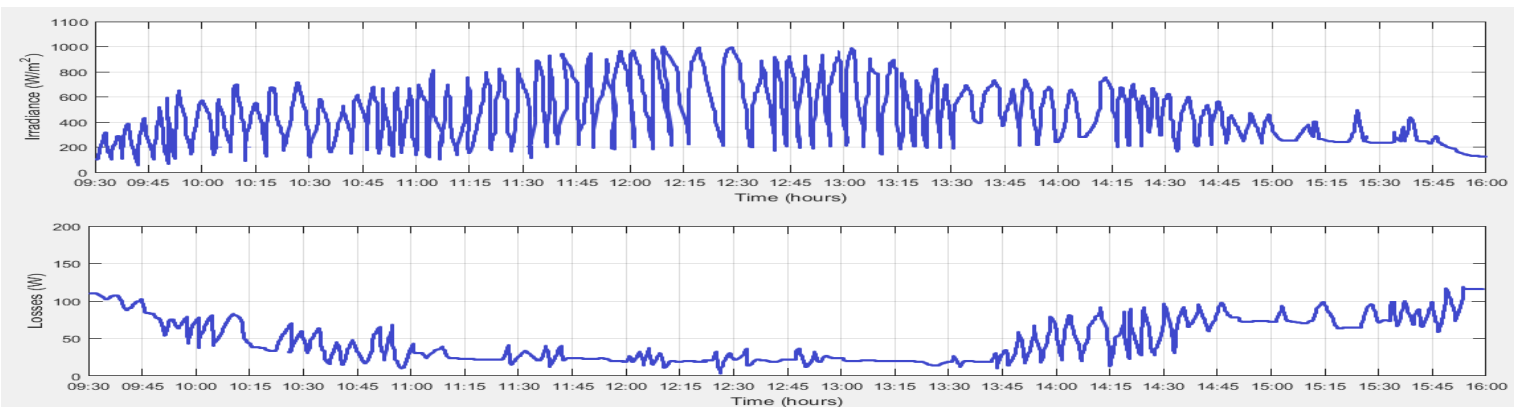

Fig.5. Losses with respect to change in level of irradiance



Fig.6. Losses in case of module fault with respect to change in level of irradiance

The change in electrical parameters on the plant side and grid side are shown in table 2 . The faults have been created in the experimental setup of the grid tied PV system so as to observer the system behaviour. The change in parameters with respect to the type of fault has been presented in this table and their location i.e. plant side or grid side can be detected easily from these parameters. The grid parameters does not affect much until there is arc fault in the cables connecting plant with grid, fault in maximum power point tracker, which effects the synchronization of plant with grid and the grid tied inverter unit containing DC/DC converter is at fault. 
TABLE 2. Change in electrical parameters of solar photovoltaic system with respect to faults

\begin{tabular}{|l|l|l|l|l|l|l|l|}
\hline \multirow{2}{*}{ Condition } & & \multicolumn{3}{|c|}{ PV Array Parameters } & \multicolumn{3}{c|}{ Grid Parameters } \\
\cline { 3 - 8 } & Nature & $\begin{array}{l}\text { Power } \\
\text { (W) }\end{array}$ & $\begin{array}{l}\text { Voltage } \\
\text { (V) }\end{array}$ & $\begin{array}{l}\text { Current } \\
(\mathbf{A})\end{array}$ & $\begin{array}{l}\text { Power } \\
\text { (W) }\end{array}$ & $\begin{array}{l}\text { Voltage } \\
\text { (V) }\end{array}$ & $\begin{array}{l}\text { Current } \\
\text { (A) }\end{array}$ \\
\hline Normal Operation & - & 290 & 56.73 & 5.13 & 1070 & 57.14 & 18.73 \\
\hline PV-Module Fault /cell fault & Internal & 224 & 47.09 & 4.70 & 1028 & 55.21 & 18.62 \\
\hline PV-Module Fault/cell fault & External & 238 & 47.80 & 4.98 & 1018 & 54.87 & 18.56 \\
\hline PV-Array Fault & Internal & 78 & 30.33 & 2.59 & 980 & 55.53 & 17.61 \\
\hline $\begin{array}{l}\text { PV-Array Fault/ one module } \\
\text { fault }\end{array}$ & External & 156 & 52.60 & 2.96 & 1009 & 56.11 & 17.98 \\
\hline Grid-Tied Inverter Fault & Internal & 112 & 36.76 & 3.04 & 997 & 54.74 & 18.23 \\
\hline $\begin{array}{l}\text { Maximum Power Point } \\
\text { Tracker Fault }\end{array}$ & Internal & 179 & 40.51 & 5.11 & 546 & 34.31 & 15.93 \\
\hline Arc- Fault in Cable & External & 63 & 29.32 & 1.13 & 467 & 42.82 & 10.91 \\
\hline
\end{tabular}

\section{CONCLUSION}

This paper is proposing the use of two variables $L_{\text {array }}$ and PR for initial reorganization of fault and distinguishing between normal and abnormal plant condition. The experimental setup has been done to check the validity of this method and to identify the type of fault and its location on plant and grid side effectively in the system. Due to this two variables method, it became easier to find the difference between internal or external system faults under different irradiance level, temperature and environmental conditions. The advantage of the proposed method is that it requires minimal set of data and it does not require any training data package. It also allows different maximum power point tracking algorithms to be integrated alongside so as to reduce the power losses and make the system efficient, reliable and safe.

\section{REFERENCES}

[1] D. Stellbogen, "Use of PV circuit simulation for fault detection in PV array fields," in Proc.23 ${ }^{\text {rd }}$ IEEE Photovoltaic Specialty Conference, Louisville, USA, 1993, p. 1302.

[2] P. Ducange, M. Fazzolari, B. Lazzerini and F. Marcelloni, "An Intelligent System for Detecting Faults in Photovoltaic Fields," in Proc. IEEE 11th International Conference on Intelligent Systems Design and Applications, Cordoba, 2011, p. 1341- 46.

[3] T. Takashima, J. Yamaguchi and M. Ishida, "Disconnection detection using earth capacitance measurement in photovoltaic module string," Progress in photovoltaics: Research and Application, vol. 16, no. 8, pp. 669-77, 2008.

[4] H. H. Khaing, Y. J. Liang, N. N. M. Htay and J. Fan, "Characteristics of different solar PV modules under partial shading," Int. Journal Elect. Computer Energetic Electron. Comm. Eng., vol. 8, no. 9, pp. 1411-15, 2014.

[5] S. Vergura, G. Acciani, V. Amoruso and G. Patrono, "Inferential Statistics for Monitoring and Fault Forecasting of PV Plants," in Proc. IEEE International Symposium, Industrial Electronics, Cambridge, 2008, p. 2414.

[6] A. Drews, A. C. de Keizer, H. G. Beyer, E. Lorenz, J. Betcke and W. G. J. H. M. van Sark, "Monitoring and Remote Failure Detection of Grid-Connected PV Systems Based on Satellite Observations," Solar Energy, vol. 81, pp. 548-64, 2007.

[7] Y. Zhao et al., "Decision tree-based fault detection and classification in solar photovoltaic arrays," in Proc. 27th Annual IEEE Appl. Power Electron. Conf. Expo., Orlando, 2012, p. 93.

[8] W. Y. Teoh and C. W. Tan, "An Overview of Islanding Detection Methods in Photovoltaic Systems," World Academy of Science, Engineering and Technology, vol. 5, pp. 10-29, 2011.

[9] K. II-Song. "Fault Detection Algorithm of the Photovoltaic System Using Wavelet Transform," in Proc. India International Conference on Power Electronics, New Delhi, 2010, p.1.

[10] A. Chouder and S. Silvestre, "Automatic Supervision and Fault Detection of PV Systems Based on Power Losses Analysis," Energy Conversion and Management, vol. 51, pp. 1929-37, 2010.

[11] Y. Zhao et al., "Fault experiments in a commercial-scale PV laboratory and fault detection using local outlier factor," in Proc. 40th IEEE Photovoltaic Spec. Conf., Denver, USA, 2014, p. 3398.

[12] S. Syafaruddin, E. Karatepe and T. Hiyama, "Controlling of Artificial Neural Network for Fault Diagnosis of Photovoltaic Array," in Proc.16th Intern. Conf. on Intelligent System App. to Power Systems, Greece, 2011, p. 1.

[13] S. Silverstre, A. Chouder and E. Karatepe, "Automatic fault detection in grid connected PV systems," Solar Energy, vol. 94, pp. 119$127,2013$.

[14] S. Armstrong and W. G. Hurley, "A thermal model for photovoltaic panels under varying atmospheric conditions," Applied Thermal Engineering, vol. 30, pp. 1488-95, 2010.

[15] S. K. Firth, K. J. Lomas and S. J. Rees, "A Simple Model of PV System Performance and Its Use in Fault Detection," Solar Energy, vol. 84 , pp. $624-35,2010$.

[16] M. K. Alam, F. Khan, J. Johnson and J. Flicker, "A comprehensive review of catastrophic faults in PV arrays: Types, detection, and mitigation techniques", IEEE Journal of Photovoltaic, vol. 5, no. 3, pp. 982-97, 2015 


\section{AUTHOR PROFILE}

Author1 Megha Khatri is presently working as Assistant Professor, School of Engineering and Technology, Ansal University. She has completed her Masters in Electrical Engineering in year 2009 from D.C.R. University of Science and Technology, Murthal, India. She has more than seve years of teaching expeiance and published research papers in the field of Power Quality, Power System, Control System and Renewable Energy Systems.

Author2 Atul Kumar is presently working as Professor, School of Engineering and Technology, Ansal University. He has earned his Ph.D. from Department of Physics in 1998 from IIT, Delhi, India. He has worked as Postdoctoral research fellow in Electrical Engineering Department at Korea Advanced Institute of Science and Technology (KAIST), South Korea. He has also worked in Research Center for Advanced Science and Technology (RCAST), University of Tokyo, Kobama Campus, Japan. He has more than 15years of research and development and teaching experience. He is a member of ISTE and Optical Society of India. 